\title{
Characteristics of Japanese Patients with Nonvalvular Atrial Fibrillation on Anticoagulant Treatment: A Descriptive Analysis of J-dabigatran Surveillance and JAPAF Study
}

\author{
Yukihiro Koretsune (D) - Koichi Kusakawa · Kouji H. Harada · Akio Koizumi - Shinichiro Uchiyama \\ Hirotsugu Atarashi · Ken Okumura · Masahiro Yasaka · Takeshi Yamashita • Atsushi Taniguchi • \\ Taku Fukaya $\cdot$ Hiroshi Inoue $\cdot$ for J-dabigatran surveillance and JAPAF study investigators
}

Received: December 13, 2018 / Published online: February 11, 2019

(C) The Author(s) 2019

\section{ABSTRACT}

Introduction: Following approval of dabigatran and other antithrombotics in Japan, few studies have specifically evaluated the clinical characteristics of patients prescribed these antithrombotics for nonvalvular atrial fibrillation (NVAF) in real-world practice.

Methods: We conducted a descriptive analysis of data from two real-world studies [J-dabigatran surveillance and Japanese study on current

Enhanced Digital Features To view enhanced digital features for this article go to https://doi.org/10.6084/ m9.figshare.7637978.

Y. Koretsune $(\bowtie)$

National Hospital Organization Osaka National

Hospital, Osaka, Japan

e-mail: koretune@onh.go.jp

K. Kusakawa · K. H. Harada · A. Koizumi Department of Health and Environmental Sciences, Kyoto University Graduate School of Medicine, Kyoto, Japan

S. Uchiyama

Clinical Research Center for Medicine, International

University of Health and Welfare, Tokyo, Japan

H. Atarashi

Minamihachioji Hospital, Tokyo, Japan

K. Okumura

Division of Cardiology, Saiseikai Kumamoto

Hospital Cardiovascular Center, Kumamoto, Japan
Anticoagulation therapies for Patients with nonvalvular Atrial Fibrillation (JAPAF); conducted at sites common to both studies] to determine the characteristics of patients with NVAF initiated on dabigatran etexilate $[110 \mathrm{mg}$ twice daily (BID; DE110) or $150 \mathrm{mg}$ BID (DE150)], warfarin, rivaroxaban, or antiplatelets as their first antithrombotic treatment. Inferential statistical analyses were not performed, and no statistical hypothesis was tested.

Results: Data for 1270 and 3011 eligible patients from the J-dabigatran surveillance (DE110, 976; DE150, 273) and JAPAF study

\author{
M. Yasaka \\ Department of Cerebrovascular Disease, Clinical \\ Research Institute, National Hospital Organization \\ Kyushu Medical Center, Fukuoka, Japan \\ T. Yamashita \\ Department of Cardiovascular Medicine, The \\ Cardiovascular Institute, Tokyo, Japan \\ A. Taniguchi · T. Fukaya \\ Medicine Division, Nippon Boehringer Ingelheim \\ Co., Ltd, Tokyo, Japan \\ H. Inoue \\ Saiseikai Toyama Hospital, Toyama, Japan
}


(warfarin, 82.5\%; rivaroxaban, 10.3\%; antiplatelets, $21 \%$ ), respectively, were extracted. In the J-dabigatran surveillance, $31.8 \%$ (full cohort, $28.1 \%$ ) of patients had been switched from warfarin to dabigatran. Among patients prescribed DE110/DE150, 41.4\%/57.5\% and $41.5 \% / 18.7 \%$ of patients had low-to-intermediate risk for ischemic stroke $\mathrm{CHADS}_{2}$ score of 0 or 1) and high risk for bleeding (HAS-BLED score $\geq 3$ ), respectively. Similarly, $33.7 \% /$ $41.3 \% / 40.2 \%$ and $48.7 \% / 42.6 \% / 75.7 \%$ of patients taking warfarin/rivaroxaban/antiplatelets had a $\mathrm{CHADS}_{2}$ score of 0 or 1 and HAS-BLED score $\geq 3$, respectively. Dabigatran was favored in patients with creatinine clearance $>50 \mathrm{ml} / \mathrm{min}$.

Conclusions: In Japan, physicians who attempt stroke prevention in patients with atrial fibrillation choose appropriate anticoagulant treatment, taking into consideration the individual patient backgrounds as well as the features of each antithrombotic agent.

Trial Registration: ClinicalTrials.gov Identifier, NCT01491178 and University Hospital Medical Information Network (UMIN) Clinical Trial Registry Identifier, UMIN000009644.

Funding: Nippon Boehringer Ingelheim Co., Ltd.

Plain Language Summary: Plain language summary available for this article.

Keywords: Anticoagulant; Dabigatran; Japan; Nonvalvular atrial fibrillation; Postmarketing surveillance

\section{PLAIN LANGUAGE SUMMARY}

Several drugs became available to prevent blood clotting and blocking of the blood supply to part of the brain (stroke) in patients having an abnormal heart rhythm (nonvalvular atrial fibrillation or NVAF). However, it is still unclear what types of patients are taking what types of drugs in daily clinical care. The authors looked into data from patients who participated in two studies conducted in Japan [1270 patients from the J-dabigatran surveillance and 3011 patients from the Japanese study on current Anticoagulation therapies for Patients with nonvalvular
Atrial Fibrillation (JAPAF)] to find out the relation between the types of patients with NVAF and the drugs for blood clotting prevention they were taking (dabigatran $110 \mathrm{mg}$ twice daily, dabigatran $150 \mathrm{mg}$ twice daily, rivaroxaban, warfarin, or antiplatelet drugs). Around $30 \%$ of the patients had changed their drug from warfarin to dabigatran. Among patients who took dabigatran $110 \mathrm{mg}$ twice daily, dabigatran $150 \mathrm{mg}$ twice daily, warfarin, rivaroxaban, and antiplatelet drugs, $41.4,57.5,33.7,41.3$, and $40.2 \%$ had low-to-intermediate risk for stroke, respectively, and 41.5, 18.7, 48.7, 42.6, and $75.7 \%$ had high risk for bleeding, respectively. Dabigatran was favored in patients having normal to mildly reduced renal function. From this research, the authors concluded that physicians in Japan choose appropriate treatment to prevent blood clotting in patients with NVAF.

\section{INTRODUCTION}

Atrial fibrillation (AF) is the most common arrhythmia in clinical practice [1], and it is estimated that the number of patients with $\mathrm{AF}$ in Japan will steadily increase to 1.03 million by 2050 [2]. Risk factors for thromboembolic and bleeding events in patients with nonvalvular AF (NVAF) and AF differ among Japanese, Western, and non-Asian populations. For example, female sex is not a risk factor for thromboembolic events, whereas male sex is a risk factor for major bleeding and all-cause mortality among Japanese patients with NVAF [3]. In addition, Japanese patients with AF have a higher risk of stroke and systemic embolism, increased prevalence of previous stroke, more bleeding events while taking warfarin (lower time spent in the therapeutic range), different target anticoagulation levels with warfarin [prothrombin time-international normalized ratio (PT-INR) $1.6-2.6$ in patients aged $\geq 70$ years], and lower body mass index (BMI) compared with nonAsians [4]. Furthermore, fewer Japanese patients with AF have hypertension or congestive heart failure, but more have diabetes mellitus, compared with non-Asians [4].

Non-vitamin K-dependent direct oral anticoagulants (DOACs; dabigatran, rivaroxaban, 
apixaban, and edoxaban) are recommended for the prevention of stroke and systemic embolism in patients with NVAF [5], where they are at least as effective and safe as warfarin [6-9]. In general, DOACs have a specific and improved risk profile compared with warfarin [10-12] and may be prescribed at suboptimal doses, depending on the bleeding risk [13].

Dabigatran was approved for reduction of the risk of stroke and systemic embolism in patients with NVAF by the United States Food and Drug Administration in 2010 [14] and by the Ministry of Health, Labour and Welfare of Japan in 2011 [15]. According to the Japanese Circulation Society (JCS), dabigatran is recommended for patients with NVAF with $\mathrm{CHADS}_{2}$ scores $\geq 1$ [5].

Following approval of dabigatran in Japan, a postmarketing surveillance (PMS) study (Jdabigatran surveillance) was initiated in December 2011 to investigate the safety and effectiveness of long-term use of dabigatran in real-world settings [16]. The Japanese study on current Anticoagulation therapies for Patients with nonvalvular Atrial Fibrillation (JAPAF) [17] was also conducted in parallel to evaluate the relationship between patient characteristics and antithrombotic therapy prescribed for the prevention of ischemic stroke and systemic embolism in Japanese patients with NVAF in daily clinical practice. Because the intention was to compare results with the J-dabigatran surveillance study, the JAPAF study did not include patients who were prescribed dabigatran.

DOACs other than dabigatran (rivaroxaban, apixaban, and edoxaban) are also approved for use in Japan; however, considering the specific differences in risk factors for thromboembolic and bleeding events in Japanese patients [3], the clinical characteristics of patients prescribed dabigatran and other antithrombotic agents remain unclear. The aim of the present study was to analyze the characteristics of Japanese patients with NVAF started on dabigatran and other antithrombotics as their initial treatment by using data from the J-dabigatran surveillance and JAPAF study.

\section{METHODS}

\section{Study Designs and Patients}

Details of the study designs and patient inclusion criteria for the J-dabigatran surveillance and JAPAF study have been reported previously $[16,17]$. For this descriptive analysis, data pertaining to patient demographics and clinical characteristics were extracted for patients with NVAF who took dabigatran etexilate [110 mg twice daily (BID; DE110) or $150 \mathrm{mg}$ BID (DE150)], warfarin, rivaroxaban (10-15 $\mathrm{mg}$ once daily), or antiplatelets as their first antithrombotic treatment. Only patients enrolled at sites common to both studies were included in this analysis. This article is based on previously conducted studies and does not contain any studies with human participants or animals performed by any of the authors.

\section{J-dabigatran Surveillance}

J-dabigatran surveillance was a prospective PMS study conducted at 1042 sites in Japan (ClinicalTrials.gov Identifier: NCT01491178). Adults with NVAF who took dabigatran for the first time between December 12, 2011, and November 30, 2013, were enrolled. Data were extracted from electric case report forms. Patients who used warfarin within 7 days prior to starting dabigatran were defined as "switchers," and those who did not use warfarin within the evaluation period were defined as "newly initiated" [16]. A total of 6772 patients were registered, of which 6443 comprised the analysis population. Patients who were ineligible for registration or who did not visit the site after the first visit were excluded.

\section{JAPAF Study}

JAPAF study was a cross-sectional study with surveillance performed between October 2011 and March 2014 [University Hospital Medical Information Network (UMIN) Clinical Trial Registry: UMIN000009644]. Patients were enrolled between April 2012 and December 2013 at 268 sites that participated in 
J-dabigatran surveillance. Adults with NVAF who received antithrombotic treatment other than dabigatran were enrolled. Patients with artificial valve replacement or valvular disease were excluded. Patient data were extracted from medical records at the first visit after registration. Of 3138 patients registered at 274 sites, 3053 were eligible; 85 were considered ineligible [17]. A full list of the investigators and study sites is available from a previously published article [17].

\section{Statistical Analysis}

Patient demographics and baseline clinical characteristics [e.g., comorbidities, creatinine clearance $(\mathrm{CrCl})$, risk of ischemic stroke $\left(\mathrm{CHADS}_{2}\right.$ score and $\mathrm{CHA}_{2} \mathrm{DS}_{2}$-VASc score), risk of bleeding (HAS-BLED score), and concomitant medication] were descriptively analyzed for the two studies and for individual initial antithrombotics (DE110, DE150, warfarin, rivaroxaban, and antiplatelets). PT-INR control in patients aged $<70$ and $\geq 70$ years was also evaluated at treatment initiation (index date) in warfarin "switchers" and those who continued on warfarin. Inferential statistical analyses were not performed, and no statistical hypothesis was tested.

\section{RESULTS}

\section{Descriptive Analysis of Patient \\ Demographics and Baseline Clinical Characteristics Between J-dabigatran Surveillance and JAPAF Study}

Data for 1270 and 3011 eligible patients from the J-dabigatran surveillance and JAPAF study, respectively, were extracted for analysis (Table 1); mean [ \pm standard deviation (SD)] age (71.1 \pm 9.3 vs. $74.1 \pm 9.4$ years, respectively) and proportion of men (66.2 vs. $66.1 \%$, respectively) were comparable between the studies. However, numerically fewer patients in the J-dabigatran surveillance than in the JAPAF study were aged $\geq 75$ years, and more patients in the J-dabigatran surveillance had paroxysmal
Table 1 Demographics and baseline clinical characteristics of patients in J-dabigatran surveillance and JAPAF study

\begin{tabular}{|c|c|c|}
\hline & $\begin{array}{l}\text { J-dabigatran } \\
\text { surveillance } \\
(n=1270)\end{array}$ & $\begin{array}{l}\text { JAPAF study } \\
(n=3011)\end{array}$ \\
\hline Male & $841(66.2)$ & $1990(66.1)$ \\
\hline \multicolumn{3}{|l|}{ Age, years } \\
\hline$<65$ & $274(21.6)$ & $467(15.5)$ \\
\hline $65-74$ & $517(40.7)$ & $980(32.5)$ \\
\hline$\geq 75$ & $479(37.7)$ & $1564(51.9)$ \\
\hline Mean \pm SD & $71.1 \pm 9.3$ & $74.1 \pm 9.4$ \\
\hline $\begin{array}{l}\text { BMI, } \mathrm{kg} / \mathrm{m}^{2} \\
\text { mean } \pm S D\end{array}$ & $24.2 \pm 3.7$ & $23.7 \pm 3.6$ \\
\hline \multicolumn{3}{|l|}{ Type of AF } \\
\hline Paroxysmal & $550(43.3)$ & $995(33.0)$ \\
\hline Persistent & $294(23.1)$ & $580(19.3)$ \\
\hline Permanent & $336(26.5)$ & $1382(45.9)$ \\
\hline Unknown & $90(7.1)^{\mathrm{a}}$ & $54(1.8)$ \\
\hline \multicolumn{3}{|l|}{ Comorbidity } \\
\hline Heart failure & $244(19.2)$ & $803(26.7)$ \\
\hline Hypertension & $905(71.3)$ & $2013(66.9)$ \\
\hline Diabetes & $280(22.0)$ & $669(22.2)$ \\
\hline Prior stroke/TIA & $242(19.1)$ & $687(22.8)$ \\
\hline Hepatic disorder & $120(9.4)$ & $193(6.4)$ \\
\hline Prior GI bleeding & $19(1.5)$ & $53(1.8)$ \\
\hline $\begin{array}{l}\text { Concomitant GI } \\
\text { disorder }\end{array}$ & $214(16.9)$ & $502(16.7)$ \\
\hline $\begin{array}{l}\text { Creatinine } \\
\text { clearance, } \mathrm{ml} / \mathrm{min}\end{array}$ & $n=1198$ & $n=1710$ \\
\hline$<30$ & $1(0.1)$ & $150(8.8)$ \\
\hline $30-50$ & $202(16.9)$ & $420(24.6)$ \\
\hline$>50$ to $<80$ & $590(49.2)$ & $770(45.0)$ \\
\hline$\geq 80$ & $405(33.8)$ & $370(21.6)$ \\
\hline Mean \pm SD & $73.3 \pm 25.8$ & $62.7 \pm 25.8$ \\
\hline \multicolumn{3}{|l|}{$\mathrm{CHADS}_{2}$ score } \\
\hline 0 & $156(12.3)$ & $295(9.8)$ \\
\hline
\end{tabular}


Table 1 continued

\begin{tabular}{|c|c|c|}
\hline & $\begin{array}{l}\text { J-dabigatran } \\
\text { surveillance } \\
(n=1270)\end{array}$ & $\begin{array}{l}\text { JAPAF study } \\
(n=3011)\end{array}$ \\
\hline 1 & $412(32.4)$ & $753(25.0)$ \\
\hline 2 & $341(26.9)$ & $877(29.1)$ \\
\hline 3 & $198(15.6)$ & $619(20.6)$ \\
\hline $4-6$ & $163(12.8)$ & $467(15.5)$ \\
\hline Mean \pm SD & $1.9 \pm 1.3$ & $2.1 \pm 1.3$ \\
\hline \multicolumn{3}{|c|}{$\mathrm{CHA}_{2} \mathrm{DS}_{2}$-VASc score } \\
\hline 0 & $49(3.9)$ & $81(2.7)$ \\
\hline 1 & $175(13.8)$ & $283(9.4)$ \\
\hline 2 & $268(21.1)$ & $543(18.0)$ \\
\hline 3 & $294(23.1)$ & $658(21.9)$ \\
\hline 4 & $235(18.5)$ & $677(22.5)$ \\
\hline $5-9$ & $249(19.6)$ & $769(25.5)$ \\
\hline Mean \pm SD & $3.1 \pm 1.7$ & $3.4 \pm 1.6$ \\
\hline \multicolumn{3}{|l|}{ HAS-BLED score } \\
\hline 0 & $78(6.1)$ & $110(3.7)$ \\
\hline 1 & $268(21.1)$ & $448(14.9)$ \\
\hline 2 & $453(35.7)$ & $954(31.7)$ \\
\hline 3 & $343(27.0)$ & $948(31.5)$ \\
\hline $4-8$ & $128(10.1)$ & $551(18.3)$ \\
\hline Mean $\pm S D$ & $2.2 \pm 1.1$ & $2.5 \pm 1.2$ \\
\hline \multicolumn{3}{|c|}{ Antithrombotic treatment } \\
\hline Dabigatran & $1270(100.0)$ & $0(0.0)$ \\
\hline Rivaroxaban & $0(0.0)$ & $310(10.3)$ \\
\hline Warfarin & $0(0.0)$ & $2484(82.5)$ \\
\hline Any antiplatelet & $0(0.0)$ & $632(21.0)$ \\
\hline \multicolumn{3}{|c|}{ Status of OAC treatment } \\
\hline Newly initiated & $852(67.1)$ & $322(10.7)$ \\
\hline Switcher & $404(31.8)$ & $125(4.2)$ \\
\hline Prevalent use & - & $2341(77.7)$ \\
\hline
\end{tabular}

Table 1 continued

\begin{tabular}{|c|c|c|}
\hline & $\begin{array}{l}\text { J-dabigatran } \\
\text { surveillance } \\
(n=1270)\end{array}$ & $\begin{array}{l}\text { JAPAF study } \\
(n=3011)\end{array}$ \\
\hline $\begin{array}{l}\text { Concomitant } \\
\text { antiplatelet with } \\
\text { OAC }\end{array}$ & $870(13.5)$ & $455(14.9)$ \\
\hline Concomitant PPI & $125(9.8)$ & $706(23.4)$ \\
\hline \multicolumn{3}{|c|}{$\begin{array}{l}\text { Data presented as } n(\%) \text { unless otherwise stated } \\
A F \text { atrial fibrillation, } B M I \text { body mass index, GI gastroin- } \\
\text { testinal, } O A C \text { oral anticoagulant, } P P I \text { proton pump inhi- } \\
\text { bitor, } S D \text { standard deviation, } T I A \text { transient ischemic } \\
\text { attack } \\
\text { a One patient had unconfirmed nonvalvular AF }\end{array}$} \\
\hline
\end{tabular}

$\mathrm{AF}$ and $\mathrm{CrCl}>50 \mathrm{ml} / \mathrm{min}$ (Table 1 ). In contrast, more patients in the JAPAF study than in the J-dabigatran surveillance had permanent $\mathrm{AF}$, $\mathrm{CrCl}<30 \mathrm{ml} / \mathrm{min}$, or were at high risk for ischemic stroke $\left(\mathrm{CHADS}_{2}\right.$ score $\geq 2 ; \mathrm{CHA}_{2} \mathrm{DS}_{2}$ VASc score $\geq 2$ ) or bleeding (HAS-BLED score $\geq 3$ ) (Table 1).

\section{Descriptive Analysis of Patient Demographics and Baseline Clinical Characteristics Based on Initial Antithrombotic/Anticoagulant Treatment}

Among patients in the J-dabigatran surveillance, the mean age was 73.1 and 63.4 years and the proportion of men was 62.2 and $81.7 \%$ in the DE110 and DE150 groups, respectively (Table 2). $\mathrm{CrCl}$ was between 30 and $50 \mathrm{ml} / \mathrm{min}$ in 20.4 and $1.6 \%$ of patients taking DE110 and DE150, respectively. $\mathrm{CrCl}$ was $<30 \mathrm{ml} / \mathrm{min}$ in $9.7,2.3$, and $10.5 \%$ of patients taking warfarin, rivaroxaban, and antiplatelets, respectively (Table 2). The majority of the patients in the J-dabigatran surveillance were newly initiated (DE110, 67.5\%; DE150, 65.2\%), and the proportions of newly initiated patients in the JAPAF study were 35.1, 9.0, and $7.2 \%$ for rivaroxaban, antiplatelets, and warfarin, respectively. Overall, a similar number of dabigatran-treated patients were switched from warfarin in the J-dabigatran surveillance at baseline. However, in the JAPAF study, only 
Table 2 Clinical characteristics and demographics of patients from each of the oral antithrombotic treatment groups

\begin{tabular}{|c|c|c|c|c|c|}
\hline & \multicolumn{2}{|c|}{ J-dabigatran surveillance } & \multicolumn{3}{|c|}{ JAPAF study } \\
\hline & $\begin{array}{l}\text { DE110 } \\
(n=976)\end{array}$ & $\begin{array}{l}\text { DE150 } \\
(n=273)\end{array}$ & $\begin{array}{l}\text { Warfarin } \\
(n=2484)\end{array}$ & $\begin{array}{l}\text { Rivaroxaban } \\
(n=310)\end{array}$ & $\begin{array}{l}\text { Antiplatelet only } \\
(n=189)\end{array}$ \\
\hline Male & $607(62.2)$ & $223(81.7)$ & $1657(66.7)$ & $183(59.0)$ & $132(69.8)$ \\
\hline \multicolumn{6}{|l|}{ Age, years } \\
\hline$<65$ & $133(13.6)$ & $139(50.9)$ & $374(15.1)$ & $59(19.0)$ & $32(16.9)$ \\
\hline $65-74$ & $393(40.3)$ & $117(42.9)$ & $814(32.8)$ & $98(31.6)$ & $62(32.8)$ \\
\hline$\geq 75$ & $450(46.1)$ & $17(6.2)$ & $1296(52.2)$ & $153(49.4)$ & $95(50.3)$ \\
\hline Mean $\pm S D$ & $73.1 \pm 8.3$ & $63.4 \pm 8.6$ & $74.2 \pm 9.3$ & $73.1 \pm 9.8$ & $73.8 \pm 10.1$ \\
\hline $\mathrm{BMI}, \mathrm{kg} / \mathrm{m}^{2}$, mean $\pm \mathrm{SD}$ & $24.1 \pm 3.7$ & $24.4 \pm 3.4$ & $23.7 \pm 3.7$ & $23.5 \pm 3.5$ & $23.6 \pm 3.7$ \\
\hline \multicolumn{6}{|l|}{ Type of AF } \\
\hline Paroxysmal & $429(44.0)$ & $113(41.4)$ & $802(32.3)$ & $112(36.1)$ & $68(36.0)$ \\
\hline Persistent & $216(22.1)$ & $70(25.6)$ & $457(18.4)$ & $65(21.0)$ & $57(30.2)$ \\
\hline Permanent & $261(26.7)$ & $70(25.6)$ & $1173(47.2)$ & $131(42.3)$ & $64(33.9)$ \\
\hline Unknown & $70(7.2)^{\mathrm{a}}$ & $20(7.3)$ & $52(2.1)$ & $2(0.6)$ & $0(0.0)$ \\
\hline \multicolumn{6}{|l|}{ Comorbidity } \\
\hline Heart failure & $197(20.2)$ & $44(16.1)$ & $685(27.6)$ & $68(21.9)$ & $43(22.8)$ \\
\hline Hypertension & $707(72.4)$ & $182(66.7)$ & $1641(66.1)$ & $215(69.4)$ & $136(72.0)$ \\
\hline Diabetes & $218(22.3)$ & $60(22.0)$ & $572(23.0)$ & $50(16.1)$ & $39(20.6)$ \\
\hline Prior stroke/TIA & $183(18.8)$ & $55(20.1)$ & $585(23.6)$ & $64(20.6)$ & $33(17.5)$ \\
\hline Hepatic disorder & $91(9.3)$ & $29(10.6)$ & $164(6.6)$ & $17(5.5)$ & $10(5.3)$ \\
\hline Prior GI bleeding & $18(1.8)$ & $1(0.4)$ & $50(2.0)$ & $3(1.0)$ & $0(0.0)$ \\
\hline Concomitant GI disorder & $175(17.9)$ & $37(13.6)$ & $405(16.3)$ & $53(17.1)$ & $37(19.6)$ \\
\hline Creatinine clearance, $\mathrm{ml} / \mathrm{min}$ & $n=922$ & $n=256$ & $n=1384$ & $n=214$ & $n=95$ \\
\hline$<30$ & $0(0.0)$ & $0(0.0)$ & $134(9.7)$ & $5(2.3)$ & $10(10.5)$ \\
\hline $30-50$ & $188(20.4)$ & $4(1.6)$ & $347(25.1)$ & $47(22.0)$ & $23(24.2)$ \\
\hline$>50$ to $<80$ & $497(53.9)$ & $87(34.0)$ & $607(43.9)$ & $113(52.8)$ & $38(40.0)$ \\
\hline$\geq 80$ & $237(25.7)$ & $165(64.5)$ & $296(21.4)$ & $49(22.9)$ & $24(25.3)$ \\
\hline Mean \pm SD & $68.8 \pm 23.7$ & $90.6 \pm 25.7$ & $62.0 \pm 26.2$ & $66.8 \pm 21.8$ & $63.9 \pm 29.0$ \\
\hline \multicolumn{6}{|l|}{$\mathrm{CHADS}_{2}$ score } \\
\hline 0 & $110(11.3)$ & $45(16.5)$ & $241(9.7)$ & $31(10.0)$ & $22(11.6)$ \\
\hline 1 & $294(30.1)$ & $112(41.0)$ & $597(24.0)$ & $97(31.3)$ & $54(28.6)$ \\
\hline 2 & $263(26.9)$ & $69(25.3)$ & $728(29.3)$ & $88(28.4)$ & $50(26.5)$ \\
\hline 3 & $166(17.0)$ & $29(10.6)$ & $521(21.0)$ & $53(17.1)$ & $37(19.6)$ \\
\hline
\end{tabular}


Table 2 continued

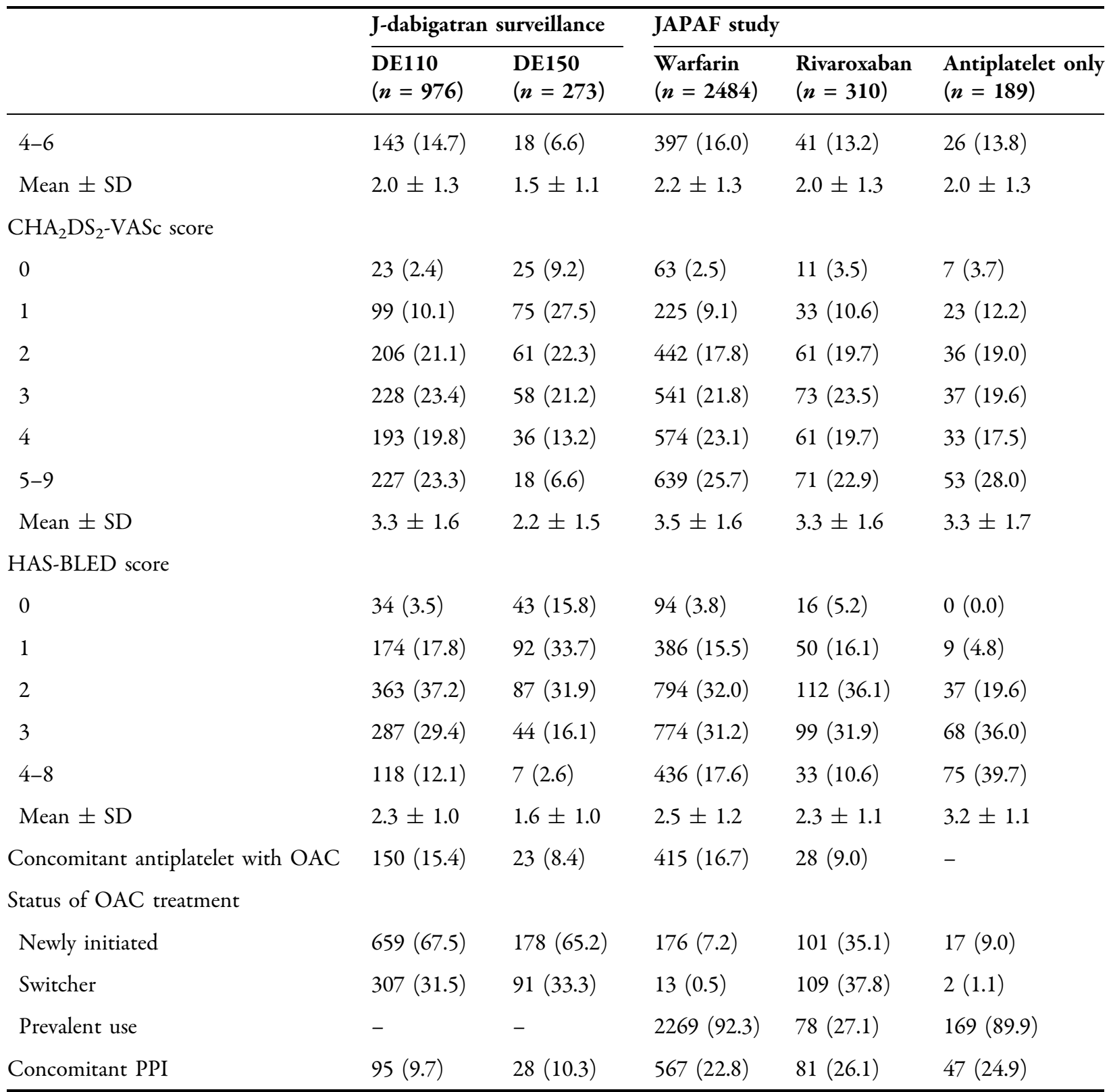

Data presented as $n(\%)$ unless otherwise stated

$A F$ atrial fibrillation, $B M I$ body mass index, $D E 110$ dabigatran etexilate $110 \mathrm{mg}$ twice daily, $D E 150$ dabigatran etexilate $150 \mathrm{mg}$ twice daily, GI gastrointestinal, $O A C$ oral anticoagulant, PPI proton pump inhibitor, SD standard deviation, TIA transient ischemic attack

a One patient had unconfirmed nonvalvular AF

$4.2 \%$ of all patients were switchers, and the majority of patients prescribed warfarin and antiplatelets continued on the same treatment (prevalent use). Most of the switchers were prescribed rivaroxaban. 
Among patients at low-to-intermediate risk for ischemic stroke $\left(\mathrm{CHADS}_{2}\right.$ score of 0 or 1 ), 41.4 and $57.5 \%$ were prescribed DE110 and DE150, respectively, in the J-dabigatran surveillance, and the lowest proportion took warfarin among other oral anticoagulants in the JAPAF study. Among patients at high risk for ischemic stroke $\left(\mathrm{CHADS}_{2} / \mathrm{CHA}_{2} \mathrm{DS}_{2}\right.$-VASc score $\geq 2$ ), $58.6 \% / 87.5 \%$ were prescribed DE110 and $42.5 \% / 63.4 \%$ were prescribed DE150 in the J-dabigatran surveillance, and warfarin was taken more often than antiplatelets or rivaroxaban in the JAPAF study. Finally, among patients at high risk for bleeding (HAS-BLED score $\geq 3$ ), most took antiplatelets, followed by warfarin and rivaroxaban in the JAPAF study, while 41.5 and $18.7 \%$ took DE110 and DE150, respectively, in the J-dabigatran surveillance (Table 2 and Fig. 1).

\section{PT-INR Control in Warfarin-treated Patients}

Only $16.4 \%$ of patients aged $<70$ years who switched from warfarin to dabigatran in the J-dabigatran surveillance had optimal PT-INR control (between 2 and 3) on the index date. In contrast, approximately half of the patients aged $<70$ years who continued on warfarin in the JAPAF study had optimal PT-INR control. More patients aged $\geq 70$ years had optimal PTINR control (between 1.6 and 2.6) on the index date in both studies (switchers in the J-dabigatran surveillance, 49.2\%; initiated and continued warfarin in the JAPAF study, $77.3 \%$ ). Suboptimal PT-INR control $(<2.0)$ was observed on the index date in more than three-quarters and half of patients aged $<70$ years in the J-dabigatran surveillance and JAPAF study, respectively. In contrast, substantially more patients aged $\geq 70$ years in the J-dabigatran surveillance than in the JAPAF study had suboptimal PT-INR control $(<1.6)$ on the index date (Table 3).

\section{DISCUSSION}

Dabigatran became available in Japan in March 2011 [15], and this large descriptive analysis
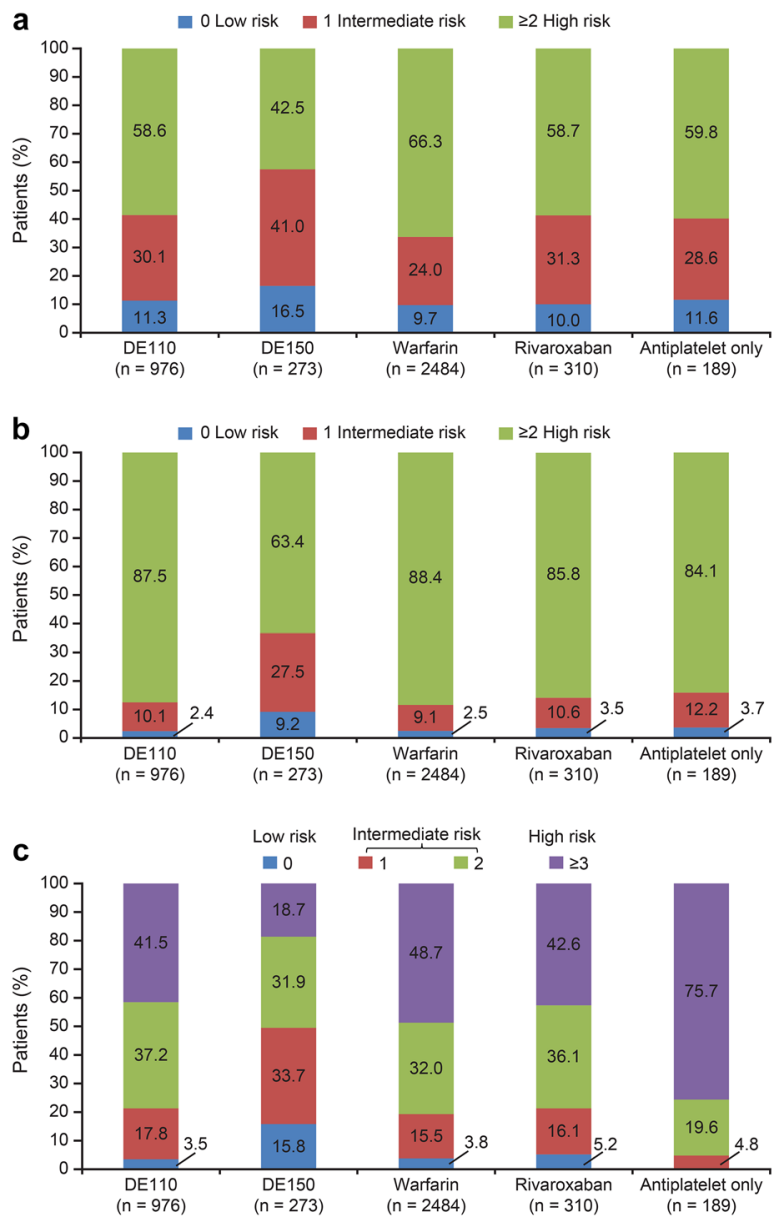

Fig. 1 Distribution of a $\mathrm{CHADS}_{2}$ score, $\mathbf{b} \mathrm{CHA}_{2} \mathrm{DS}_{2}$ VASc score, and c HAS-BLED score in patients prescribed DE110, DE150, warfarin, rivaroxaban, or antiplatelet only. $D E 110$ dabigatran etexilate $110 \mathrm{mg}$ twice daily, $D E 150$ dabigatran etexilate $150 \mathrm{mg}$ twice daily

represents the first evaluation of the real-world characteristics of Japanese patients with NVAF treated with dabigatran (DE110 or DE150) [18] or other antithrombotic medications after approval of dabigatran. In the JAPAF study, the majority of patients were continued on warfarin treatment, and the study included a higher percentage of patients aged $\geq 75$ years. With respect to type of $\mathrm{AF}$, most patients prescribed dabigatran had paroxysmal $\mathrm{AF}$, followed by permanent $\mathrm{AF}$ and vice versa for anticoagulant prescriptions in the JAPAF study. In the J-dabigatran surveillance, physicians chose dabigatran for patients with higher average $\mathrm{CrCl}$ in contrast to the JAPAF study where patients with 
Table 3 Prothrombin time-international normalized ratio control based on age of warfarin-treated patients

\begin{tabular}{lll}
\hline & $\begin{array}{l}\text { J-dabigatran } \\
\text { surveillance }^{\mathbf{a}} \\
(\boldsymbol{n}=\mathbf{3 5 9})\end{array}$ & $\begin{array}{l}\text { JAPAF study }^{\mathbf{b}} \\
(\boldsymbol{n}=\mathbf{2 4 5 5})\end{array}$ \\
\hline PT-INR control & & $n=725$ \\
Aged $<70$ years & $n=116$ & $364(50.2)$ \\
$<2.0$ & $95(81.9)$ & $344(47.4)$ \\
$2.0-3.0$ & $19(16.4)$ & $17(2.3)$ \\
$>3.0$ & $2(1.7)$ & $n=1730$ \\
Aged $\geq 70$ years & $n=193$ & $271(15.7)$ \\
$<1.6$ & $92(47.7)$ & $1338(77.3)$ \\
$1.6-2.6$ & $95(49.2)$ & $121(7.0)$ \\
$>2.6$ & $6(3.1)$ &
\end{tabular}

Data presented as $n$ (\%)

PT-INR prothrombin time-international normalized ratio

${ }^{a}$ Patients with available data who switched from warfarin to dabigatran at index date

b Patients with available data who initiated and continued warfarin

$\mathrm{CrCl} \leq 50 \mathrm{ml} / \mathrm{min}$ were more common. As anticipated, newly initiated cases were more common than switched cases in the J-dabigatran surveillance. In the JAPAF study, physicians chose to continue patients on their long-term warfarin prescriptions, suggesting good PT-INR control and lack of perceived need to switch.

It appears that physicians are prescribing according to the Japanese label that recommends an oral dose of dabigatran $150 \mathrm{mg}$ BID in adults. However, for patients with moderate renal impairment $(\mathrm{CrCl} 30-50 \mathrm{ml} / \mathrm{min})$ and those taking an oral P-glycoprotein inhibitor, a lower dose of $110 \mathrm{mg}$ BID is recommended. The Japanese label also recommends administering the $110 \mathrm{mg}$ BID dose with care in patients aged $\geq 70$ years or in those with a history of gastrointestinal hemorrhage [15]. Similarly, the recommended dose of rivaroxaban in patients with NVAF is $15 \mathrm{mg} /$ day for adults with $\mathrm{CrCl}>50 \mathrm{ml} / \mathrm{min}$ and $10 \mathrm{mg} /$ day for $\mathrm{CrCl}$ $30-49 \mathrm{ml} / \mathrm{min}$ per the Japanese label. Caution should be exercised with the $10 \mathrm{mg} /$ day dose in patients with $\mathrm{CrCl} 15-29 \mathrm{ml} / \mathrm{min}$ [19]. This analysis suggests that in patients with reduced renal function $(\mathrm{CrCl}<50 \mathrm{ml} / \mathrm{min})$, DE110 was more commonly prescribed than DE150 among patients in the J-dabigatran surveillance, and warfarin and antiplatelets were more commonly prescribed than rivaroxaban in the JAPAF study. DOACs were more often prescribed to those with $\mathrm{CrCl} \geq 50 \mathrm{ml} / \mathrm{min}$. Furthermore, a higher dose of dabigatran was administered, particularly in patients with $\mathrm{CrCl} \geq 50 \mathrm{ml} / \mathrm{min}$.

The JCS recommends DOACs such as dabigatran or warfarin for patients with NVAF at high risk for ischemic stroke $\left(\mathrm{CHADS}_{2}\right.$ score $\geq 2$ ) [5]. These antithrombotic agents may also be considered in patients with other risk factors [e.g., cardiomyopathy, age 65-74 years, and vascular disease (prior myocardial infarction, aortic plaque, and peripheral vascular disease)]. Further, dabigatran and apixaban are recommended, and rivaroxaban, edoxaban, and warfarin may be considered, in patients at intermediate risk for ischemic stroke $\mathrm{CHADS}_{2}$ score of 1). The JCS also states that the $\mathrm{CHADS}_{2}$ score can be used to accurately identify patients who are at high risk for ischemic stroke; however, this clinical prediction measure is less accurate for low-risk patients [5]. Patients at low-to-intermediate risk $\left(\mathrm{CHADS}_{2}\right.$ score of 0 or 1) account for approximately half of patients with NVAF, but the efficacy of warfarin in these patients has not been established [20]. Contrary to these recommendations, $9.7-12.3 \%$ of patients at low risk $\left(\mathrm{CHADS}_{2}\right.$ score of 0$)$ were prescribed warfarin in both studies, indicating physicians' discretion or a cautious preventive measure in these patients. DOACs were marginally favored over warfarin and antiplatelets in patients at intermediate risk $\left(\mathrm{CHADS}_{2}\right.$ score of 1) for ischemic stroke. This suggests a transition towards the use of newer anticoagulants compared to warfarin and antiplatelets in lowrisk patients. However, considering the years that were evaluated for data collection, warfarin was more commonly prescribed for patients with a higher risk of ischemic stroke, and also for patients who were elderly and had more comorbidities.

Overall, these results should be evaluated considering the rate of knowledge dissemination and physicians' concerns during the 
transition period when the newer anticoagulants were introduced.

The JCS also recommends a PT-INR of 1.6-2.6 with warfarin in patients with NVAF aged $\geq 70$ years [5]. For those aged $<70$ years, a PT-INR between 2 and 3 should be maintained. Among patients aged $<70$ years, only $16.4 \%$ of patients who switched from warfarin to dabigatran in the J-dabigatran surveillance had optimal PT-INR control (between 2.0 and 3.0) on the index date. However, half of the warfarin users aged $<70$ years in the JAPAF study had optimal PT-INR control. In addition, optimal PT-INR control (between 1.6 and 2.6) with warfarin was observed in considerably fewer patients aged $\geq 70$ years in the $\mathrm{J}$-dabigatran surveillance than in the JAPAF study. These results suggest that warfarin did not produce optimal PT-INR in these age groups, necessitating a switch to another antithrombotic drug. The results also suggest that most patients with suboptimal PTINR control may have been switched to dabigatran, although the J-dabigatran surveillance had constraints of only including switched patients from warfarin. These results are also important for other Asia-Pacific countries because, although international guidelines recommend that the optimal PT-INR of warfarin is 2.0-3.0, the practice in Asia-Pacific countries (excluding Australia and New Zealand) follows the JCS guidelines; therefore, the Asia Pacific Heart Rhythm Society 2013 statement also recommends an PT-INR of 1.6-2.6 for patients aged $\geq 70$ years [21].

Finally, the JCS asserts that in patients aged $>75$ years taking anticoagulants, low body weight $(\leq 50 \mathrm{~kg}), \mathrm{CrCl} \leq 50 \mathrm{ml} / \mathrm{min}$, and use of antiplatelets are major risk factors for bleeding [5]. Antiplatelets are expected to prevent only lacunar infarction and minor infarction associated with atherothrombotic infarction [22]. They are not recommended as first-line therapy for patients with $\mathrm{AF}$ and should be considered only when anticoagulation cannot be used. In an analysis of data from the J-RHYTHM registry, antiplatelet use was a negative determinant of warfarin use, suggesting some physicians use antiplatelets as an alternative to warfarin for prevention of thromboembolism in patients with AF in Japan [23]. In the current analysis, 189 patients in the
JAPAF study were prescribed antiplatelets. Among these patients, more than half $(59.8 \%)$ were at high risk for ischemic stroke and threequarters $(75.7 \%)$ were at high risk for bleeding.

\section{Limitations}

Data were analyzed descriptively, and no statistical analyses were performed. Further, direct comparison was made among subgroups from two different studies. Patient background data were analyzed immediately after DOAC administration became available in Japan. Therefore, as time has elapsed since both studies were conducted, it is possible that the physicians' treatment trends have already changed. Nevertheless, the study does reflect the surveillance period of the anticoagulant prescriptions in patients with NVAF when knowledge of newer agents was disseminated and incorporated into the guidelines. Finally, generalizability of our results may be limited because this study included only Japanese patients with NVAF.

\section{CONCLUSIONS}

The results of this descriptive analysis of the transition phase when newer anticoagulants were introduced suggest that most patients prescribed dabigatran were newly diagnosed, non-elderly, and with good renal function. On the other hand, antithrombotic agents, especially warfarin, were continued long-term for patients who were elderly and/or with long duration of $\mathrm{AF}$, with relatively favorable PT-INR control. In addition, patients with high risk of both stroke and bleeding continued treatment with antiplatelets only. These findings suggest that physicians aiming to prevent stroke in patients with AF choose appropriate anticoagulant treatment, taking into consideration individual patient backgrounds as well as the features of each antithrombotic agent.

\section{ACKNOWLEDGEMENTS}

We thank the participants of the studies. 
Funding. This study was conducted under the sponsorship of Nippon Boehringer Ingelheim Co., Ltd. Article processing charges were funded by Nippon Boehringer Ingelheim Co., Ltd. All authors had full access to all of the data in this study and take complete responsibility for the integrity of the data and accuracy of the data analysis.

Medical Writing, Editorial, and Other Assistance. Editorial support, in the form of medical writing, assembling tables and creating high-resolution images based on authors' detailed directions, collating author comments, copyediting, fact checking, and referencing, was provided by Annirudha Chillar, MD, PhD, and Maribeth Bogush, PhD, of Cactus Communications. Support for this assistance was funded by Nippon Boehringer Ingelheim Co., Ltd.

Authorship. All named authors meet the International Committee of Medical Journal Editors (ICMJE) criteria for authorship for this article, take responsibility for the integrity of the work as a whole, and have given their approval for this version to be published.

List of Investigators. A full list of the investigators and study sites is available from a previously published article [17].

Disclosures. Yukihiro Koretsune has received remuneration from Daiichi Sankyo, Boehringer Ingelheim, Bayer Healthcare, Bristol-Myers Squibb, and Pfizer. Koichi Kusakawa was an employee of Nippon Boehringer Ingelheim until January 2013 and currently works in the Department of Health and Environmental Sciences, Kyoto University Graduate School of Medicine, Kyoto, Japan. Kouji H. Harada has received research funding from Boehringer Ingelheim. Akio Koizumi has received research funding from Boehringer Ingelheim. Shinichiro Uchiyama has received remuneration from Boehringer Ingelheim, Bayer Healthcare, Daiichi Sankyo, and Sanofi. Hirotsugu Atarashi has received remuneration from Boehringer Ingelheim and Daiichi Sankyo. Ken Okumura has received remuneration from Boehringer Ingelheim, Bayer Healthcare, Daiichi Sankyo, and
Pfizer. Masahiro Yasaka has received remuneration from Boehringer Ingelheim, Bayer Healthcare, and Daiichi Sankyo, and research funding from Boehringer Ingelheim. Takeshi Yamashita has received remuneration from Boehringer Ingelheim, Daiichi Sankyo, Bayer Healthcare, Pfizer, and Bristol-Myers Squibb, and research funding from Daiichi Sankyo, Bayer Healthcare, and Bristol-Myers Squibb. Atsushi Taniguchi is an employee of Nippon Boehringer Ingelheim. Taku Fukaya is an employee of Nippon Boehringer Ingelheim. Hiroshi Inoue has received remuneration from Boehringer Ingelheim, Bayer Healthcare, Daiichi Sankyo, and BristolMyers Squibb.

Compliance with Ethics Guidelines. This article is based on previously conducted studies and does not contain any studies with human participants or animals performed by any of the authors.

Data Availability. The datasets generated and/or analyzed during the current study are available from the corresponding author on reasonable request.

Open Access. This article is distributed under the terms of the Creative Commons Attribution-NonCommercial 4.0 International License (http://creativecommons.org/licenses/ by-nc/4.0/), which permits any noncommercial use, distribution, and reproduction in any medium, provided you give appropriate credit to the original author(s) and the source, provide a link to the Creative Commons license, and indicate if changes were made.

\section{REFERENCES}

1. Kodani E, Atarashi H. Prevalence of atrial fibrillation in Asia and the world. J Arrhythm. 2012;28(6):330-7.

2. Inoue $\mathrm{H}$, Fujiki $\mathrm{A}$, Origasa $\mathrm{H}$, et al. Prevalence of atrial fibrillation in the general population of Japan: an analysis based on periodic health examination. Int J Cardiol. 2009;137(2):102-7. 
3. Inoue $\mathrm{H}$, Atarashi $\mathrm{H}$, Okumura $\mathrm{K}$, et al. Impact of gender on the prognosis of patients with nonvalvular atrial fibrillation. Am J Cardiol. 2014;113(6):957-62.

4. Gómez-Molina M, Valdés M, Marín F. Oral anticoagulation in Japanese patients with atrial fibrillation-insight to the use of non-vitamin $\mathrm{K}$ antagonist oral anticoagulants. Circ J. 2015;79(2):292-4.

5. JCS Joint Working Group. Guidelines for pharmacotherapy of atrial fibrillation (JCS 2013). Circ J. 2014;78(8):1997-2021.

6. Connolly SJ, Ezekowitz MD, Yusuf S, et al. Dabigatran versus warfarin in patients with atrial fibrillation. N Engl J Med. 2009;361(12):1139-51.

7. Granger $\mathrm{CB}$, Alexander JH, McMurray JJ, et al. Apixaban versus warfarin in patients with atrial fibrillation. N Engl J Med. 2011;365(11):981-92.

8. Patel MR, Mahaffey KW, Garg J, et al. Rivaroxaban versus warfarin in nonvalvular atrial fibrillation. N Engl J Med. 2011;365(10):883-91.

9. Giugliano RP, Ruff CT, Braunwald E, et al. Edoxaban versus warfarin in patients with atrial fibrillation. N Engl J Med. 2013;369(22):2093-104.

10. Graham DJ, Reichman ME, Wernecke $M$, et al. Cardiovascular, bleeding, and mortality risks in elderly Medicare patients treated with dabigatran or warfarin for nonvalvular atrial fibrillation. Circulation. 2015;131(2):157-64.

11. Lip GY, Pan X, Kamble S, et al. Major bleeding risk among non-valvular atrial fibrillation patients initiated on apixaban, dabigatran, rivaroxaban or warfarin: a "real-world" observational study in the United States. Int J Clin Pract. 2016;70(9):752-63.

12. Sharma M, Cornelius VR, Patel JP, Davies JG, Molokhia M. Efficacy and harms of direct oral anticoagulants in the elderly for stroke prevention in atrial fibrillation and secondary prevention of venous thromboembolism: systematic review and meta-analysis. Circulation. 2015;132(3):194-204.

13. Umei $M$, Kishi $M$, Sato $T$, et al. Indications for suboptimal low-dose direct oral anticoagulants for non-valvular atrial fibrillation patients. J Arrhythm. 2017;33(5):475-82.
14. Pradaxa $^{\circledR}$ (package insert). Revised March 2018. http://docs.boehringer-ingelheim.com/

Prescribing\%20Information/PIs/Pradaxa/Pradaxa. pdf. Accessed 28 Nov 2018.

15. $\operatorname{Prazaxa}^{\circledR}$ (Japanese package insert). http://www. info.pmda.go.jp/go/pack/3339001M1024_1_12/. Accessed 28 Nov 2018.

16. Inoue $\mathrm{H}$, Uchiyama $\mathrm{S}$, Atarashi $\mathrm{H}$, et al. Post-marketing surveillance on the long-term use of dabigatran in Japanese patients with nonvalvular atrial fibrillation: preliminary report of the J-dabigatran surveillance. J Arrhythm. 2016;32(2):145-50.

17. Kusakawa K, Harada KH, Kagimura T, Koizumi A. Major determinants for the selecting antithrombotic therapies in patients with nonvalvular atrial fibrillation in Japan (JAPAF study). J Arrhythm. 2017;33(2):99-106.

18. Suzuki S, Otsuka T, Sagara K, et al. Dabigatran in clinical practice for atrial fibrillation with special reference to activated partial thromboplastin time. Circ J. 2012;76:755-7.

19. Xarelto ${ }^{\circledR}$ (package insert). http://www.info.pmda. go.jp/go/pack/3339003F1024_1_15/. Accessed 28 Nov 2018.

20. Olesen JB, Lip GY, Hansen ML, et al. Validation of risk stratification schemes for predicting stroke and thromboembolism in patients with atrial fibrillation: nationwide cohort study. BMJ. 2011;342:d124.

21. Ogawa S, Aonuma K, Tse H-F, et al. The APHRS's 2013 statement on antithrombotic therapy of patients with nonvalvular atrial fibrillation. J Arrhythm. 2013;29:190-200.

22. Sato H, Ishikawa K, Kitabatake A, et al. Low-dose aspirin for prevention of stroke in low-risk patients with atrial fibrillation: Japan Atrial Fibrillation Stroke Trial. Stroke. 2006;37(2):447-51.

23. J-RHYTHM Registry Investigators. Determinants of warfarin use and international normalized ratio levels in atrial fibrillation patients in Japan-subanalysis of the J-RHYTHM Registry. Circ J. 2011;75(10):2357-62. 